\title{
Targeted sequencing of tonsillar and base of tongue cancer and human papillomavirus positive unknown primary of the head and neck reveals prognostic effects of mutated FGFR3
}

\author{
Cinzia Bersani ${ }^{1}$, Lars Sivars ${ }^{1}$, Linnea Haeggblom ${ }^{1}$, Sebastian DiLorenzo ${ }^{2,3}$, Michael \\ Mints $^{4,5}$, Andreas Ährlund-Richter ${ }^{1}$, Nikolaos Tertipis ${ }^{1}$, Eva Munck-Wikland ${ }^{6,7}$, \\ Anders Näsmann ${ }^{1}$, Torbjörn Ramqvist ${ }^{1, *}$ and Tina Dalianis ${ }^{1, *}$ \\ 1 Department of Oncology-Pathology, Karolinska Institutet, Stockholm, Sweden \\ 2 Department of Medical Sciences, Uppsala University, Uppsala, Sweden \\ ${ }^{3}$ National Bioinformatics Infrastructure Sweden, Science for Life Laboratory, Uppsala University, Uppsala, Sweden \\ ${ }^{4}$ Department of Medicine, Karolinska Institutet, Stockholm, Sweden \\ ${ }^{5}$ Department of Surgical and Perioperative Sciences, Umeå University, Umeå, Sweden \\ ${ }^{6}$ Department of Clinical Science and Technology, Karolinska Institutet, Stockholm, Sweden \\ 7 Department of Oto-Rhino-Laryngology, Head and Neck Surgery, Karolinska University Hospital, Stockholm, Sweden \\ * These authors have contributed equally to this work \\ Correspondence to: Cinzia Bersani, email: Cinzia.Bersani@ki.se \\ Keywords: HPV, tonsillar cancer, base of tongue cancer, cancer of unknown primary of the head and neck region, FGFR3 muta- \\ tion \\ Received: December 21,2016 Accepted: January 24, $2017 \quad$ Published: February 09, 2017
}

Copyright: Bersani et al. This is an open-access article distributed under the terms of the Creative Commons Attribution License (CC-BY), which permits unrestricted use, distribution, and reproduction in any medium, provided the original author and source are credited.

\section{ABSTRACT}

BACKGROUND: Human papillomavirus positive ( $\mathrm{HPV}^{+}$) tonsillar cancer (TSCC), base of tongue cancer (BOTSCC) and unknown primary cancer of the head and neck (HNCUP) have better outcome than corresponding HPV- cancers. To find predictive markers for response to treatment, and correlations and differences in mutated oncogenes and suppressor genes between HPV + TSCC/BOTSSCC and HPV + HNCUP and HPV- TSCC/BOTSCC targeted next-generation sequencing was performed of frequently mutated regions in $\mathbf{5 0}$ cancer related genes.

PATIENTS AND METHODS: DNA from 348 TSCC/BOTSCC and 20 HNCUP from patients diagnosed 2000-2011, was sequenced by the Ion Proton sequencing platform using the Ion AmpliSeq Cancer Hotspot Panel v2 to identify frequently mutated regions in $\mathbf{5 0}$ cancer related genes. Ion Torrent Variant Caller software was used to call variants.

RESULTS: 279 HPV+ TSCC/BOTSCC, 46 HPV- TSCC/BOTSCC and 19 HPV+ HNCUP samples qualified for further analysis. Mutations/tumor were fewer in $\mathrm{HPV}^{+} \mathrm{TSCC}$ BOTSCC and HNCUP, compared to HPV- tumors (0.92 vs. 1.32 vs. 1.68). Differences in mutation frequency of TP53 and PIK3CA were found between HPV ${ }^{+}$TSCC/BOTSCC and HNCUP and HPV- TSCC/BOTSCC. In HPV ${ }^{+}$TSCC/BOTSCC presence of FGFR3 mutations correlated to worse prognosis. Other correlations to survival within the groups were not disclosed.

CONCLUSIONS: In HPV + TSCC/BOTSCC mutation of PIK3CA was most frequently observed, while TP53 mutations dominated in HPV- TSCC/BOTSCC. In HPV+ TSCC/ BOTSCC and HNCUP, mutations/tumor were similar in frequency and fewer compared to that in HPV- TSCC/BOTSCC. Notably, FGFR3 mutations in HPV ${ }^{+}$TSCC/BOTSCC indicated worse prognosis. 


\section{INTRODUCTION}

Human papillomavirus positive $\left(\mathrm{HPV}^{+}\right)$tonsillar squamous cell carcinoma (TSCC) and base of tongue squamous cell carcinoma (BOTSCC) and head neck unknown primary cancer (HNCUP) have a much better clinical outcome than the corresponding HPV tumors and some other types of head and neck squamous cell carcinoma (HNSCC) [1-6]. Furthermore, the incidences of TSCC and BOTSCC, the two subtypes of oropharyngeal squamous cell carcinoma (OPSCC), where HPV is most frequently found, have increased considerably in many Western countries [5-14]. HNSCC therapy is today often aggressive with radiotherapy, induction/ concomitant chemoradiotherapy, targeted therapy and surgery. However, most $\mathrm{HPV}^{+} \mathrm{TSCC} / \mathrm{BOTSCC}$ and HNCUP patients do not need intensified treatment, and the possibility to de-escalate, or better tailor treatment, while maintaining survival and reducing treatment-related morbidity would be of significant benefit [5].

To better individualize treatments, several efforts have been made to identify additional predictive markers [15-23]. Age, stage, smoking, presence of HPV16 E2 mRNA, absent/low HLA class I expression, CD44, LMP10 expression, high LRIG1 expression, absence of HLA-A*02, high $\mathrm{CD}^{+}$tumor infiltrating lymphocyte (TIL) counts and CD98 have been proposed as such markers in $\mathrm{HPV}^{+} \mathrm{TSCC}$ and BOTSCC [15-25]. One by one, or in combination in mathematical models, they can identify $20-40 \%$ of patients with up to $>95 \%$ probability to have a 3-year disease free survival in $\mathrm{HPV}^{+} \mathrm{TSCC} /$ BOTSCC [24]. However, additional markers are necessary to distinguish a larger proportion of patients with tumors with a very high probability to respond easily and thoroughly to therapy. Furthermore, the search for new markers may very well lead to the disclosure of specific proteins and/or mutations in genes that could be targeted by existing or novel targeted therapies.

In the case of $\mathrm{HPV}^{+} \mathrm{HNCUP}$, since its survival after treatment is similar to that of $\mathrm{HPV}^{+} \mathrm{TSCC} / \mathrm{BOTSCC}$, one hypothesis put forward is that it may originate from an $\mathrm{HPV}^{+}$TSCC or BOTSCC [4, 26-28]. Nevertheless, so far there is limited evidence of the exact nature of $\mathrm{HPV}^{+}$ HNCUP and there are studies that have not found the same impact of HPV on survival [29].

To find more predictive markers for response to therapy for $\mathrm{HPV}^{+} \mathrm{TSCC} / \mathrm{BOTSCC}$, and similarities and differences of mutated genes compared to $\mathrm{HPV}^{+} \mathrm{HNCUP}$ and $\mathrm{HPV}^{-} \mathrm{TSCC} / \mathrm{BOTSCC}$, as well as potential targets for new therapies, next-generation sequencing (NGS) of hotspot mutations in 50 cancer related genes, was done. Examining TP53 and PIK3CA was of special interest, since these genes have previously been reported to be differentially mutated in $\mathrm{HPV}^{+}$and $\mathrm{HPV}^{-}$OPSCC and their impact on outcome at the genomic level has not been studied extensively in $\mathrm{HPV}^{+}$and HPV OPSCC [30].

\section{RESULTS}

\section{Next-generation sequencing, calling and filtering of variants}

DNA from 368 formalin-fixed paraffin-embedded (FFPE) tumor samples including $297 \mathrm{HPV}^{+}$and $51 \mathrm{HPV}^{-}$ TSCC/BOTSCC and $20 \mathrm{HPV}^{+} \mathrm{HNCUP}$ was analyzed using the Ion AmpliSeq Cancer Hotspot Panel v2 (CHPv2) covering hotspot regions from 50 oncogenes and tumor suppressor genes. After excluding 24 samples due to poor DNA quality, $279 \mathrm{HPV}^{+}$, $46 \mathrm{HPV}^{-} \mathrm{TSCC} / \mathrm{BOTSCC}$ and $19 \mathrm{HPV}^{+} \mathrm{HNCUP}$ samples remained for further analysis. Patient and tumor characteristics for the included samples are presented in Table 1 (TSCC and BOTSCC) and Table 2 (HNCUP) and in more detail in the material and methods section. Of the $279 \mathrm{HPV}$ DNA positive TSCC/BOTSCC samples, 255 were HPV16 positive, while the remaining were HPV33, 35, 56, 58 or 59 positive and all but one overexpressed p16. All HNCUP samples were HPV16 positive and all but two overexpressed $\mathrm{p} 16$.

Variants were called using the Torrent Variant Caller (TVC) version 5.0 and after filtering for $>5 \%$ allele frequency and an allele coverage of $>100$ the remaining variants were filtered against several population genome databases as specified in the materials and methods section.

\section{Variants in $\mathrm{HPV}^{+}$and $\mathrm{HPV}^{-}$TSCC/BOTSCC exhibit differences based on HPV status}

After filtering, 337 variants remained in $325 \mathrm{TSCC} /$ BOTSCC distributed in the different target genes as presented in Table 3. In $\mathrm{HPV}^{+} \mathrm{TSCC} / \mathrm{BOTSCC}$, the most common variants were PIK3CA, TP53, FGFR3, FBXW7, PTEN and CDKN2A, while in HPV TSCC/BOTSCC mutations were most frequently found in TP53, PIK3CA, IDH2, ABL1, BRAF, CDKN2A, EGFR, NOTCH1 and PTPN11. Significant differences in frequency of variants between the two groups are shown in Table 3. Variants were more common in $\mathrm{HPV}^{-}$than in $\mathrm{HPV}^{+} \mathrm{TSCC} /$ BOTSCC with 0.92 vs. 1.68 variant/tumor respectively and were detected in $48.7 \%(136 / 279)$ of $\mathrm{HPV}^{+}$and $74.5 \%$ $(35 / 46)$ of the HPV cases $(p=0.0007)$. This difference was mainly due to the difference in TP53 variants $(9.3 \%$ $v s .63 .8 \%$ for $\mathrm{HPV}^{+} v$ s. HPV- TSCC/BOTSCC). Non-TP53 mutations tended to be more frequent in $\mathrm{HPV}^{+}$compared to HPV TSCC/BOTSCC ( $46.6 \%$ vs. $30.4 \%, p=0.0538$ ). PIK3CA was the most frequently mutated gene in $\mathrm{HPV}^{+}$ TSCC/BOTSCC and was significantly more frequently mutated in $\mathrm{HPV}^{+}$than in $\mathrm{HPV}^{-} \mathrm{TSCC} / \mathrm{BOTSCC}(20.1 \%$ vs. $6.4 \%$ ). As presented in Table 3, two more genes IDH2 and NOTCH1, also showed significant differences in numbers of variants between $\mathrm{HPV}^{+}$and HPV TSCC/BOTSCC, but 
in these cases the numbers of affected tumors were small and the data should be treated with caution. Differences between the two groups are visualized in Supplementary Figure S1.

Spearman correlations were calculated between the presence of any mutation in the genes analyzed and HPV status. It was found that a number of genes (ERBB4, FLT3, HNF1A, IDH1 etc.) are mutated in highly correlated blocks, and that most of these mutations are absent in patients with $\mathrm{HPV}^{+}$TSCC/BOTSCC. TP53 mutations had the strongest inverse correlation with $\mathrm{HPV}^{+} \mathrm{TSCC} /$ BOTSCC, while PIK3CA and FBXW7 showed positive correlations (Figure 1).

\section{Variants in $\mathrm{HPV}^{+}$HNCUP}

In the $19 \mathrm{HPV}^{+} \mathrm{HNCUP}, 25$ variants (1.32 variants/ tumor) were observed in TP53, PIK3CA, CDKN2A, EGFR, IDH2, FBXW7 and VHL, for details see Table
3. In total, $47 \%(9 / 19)$ of the tumors contained variants, which was similar to the frequency in $\mathrm{HPV}^{+} \mathrm{TSCC} /$

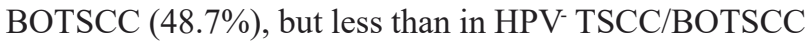
$(74.5 \%)(p=0.04)$. TP53 was more often mutated in $\mathrm{HPV}^{+}$ HNCUP than in $\mathrm{HPV}^{+}$TSCC/BOTSCC $(p=0.0345)$, but less often than in HPV- TSCC/BOTSCC $(p=0.0061)$. The frequency of mutated PIK3CA was similar to that in $\mathrm{HPV}^{+}$ TSCC/BOTSCC.

\section{Clinical response in relation to variant genes indicates a role of FGFR3}

Survival analysis was performed for the $277 \mathrm{HPV}^{+}$ TSCC/BOTSCC patients treated with curative intent for genes with mutations in $>6 \%$ of the cases i.e. TP53, PIK3CA, FGFR3, FBXW7 and of which three (TP53, FGFR3 and PIK3CA) are potentially targetable. A significant correlation to clinical response was found for variants in FGFR3, but for none of the other tested genes.

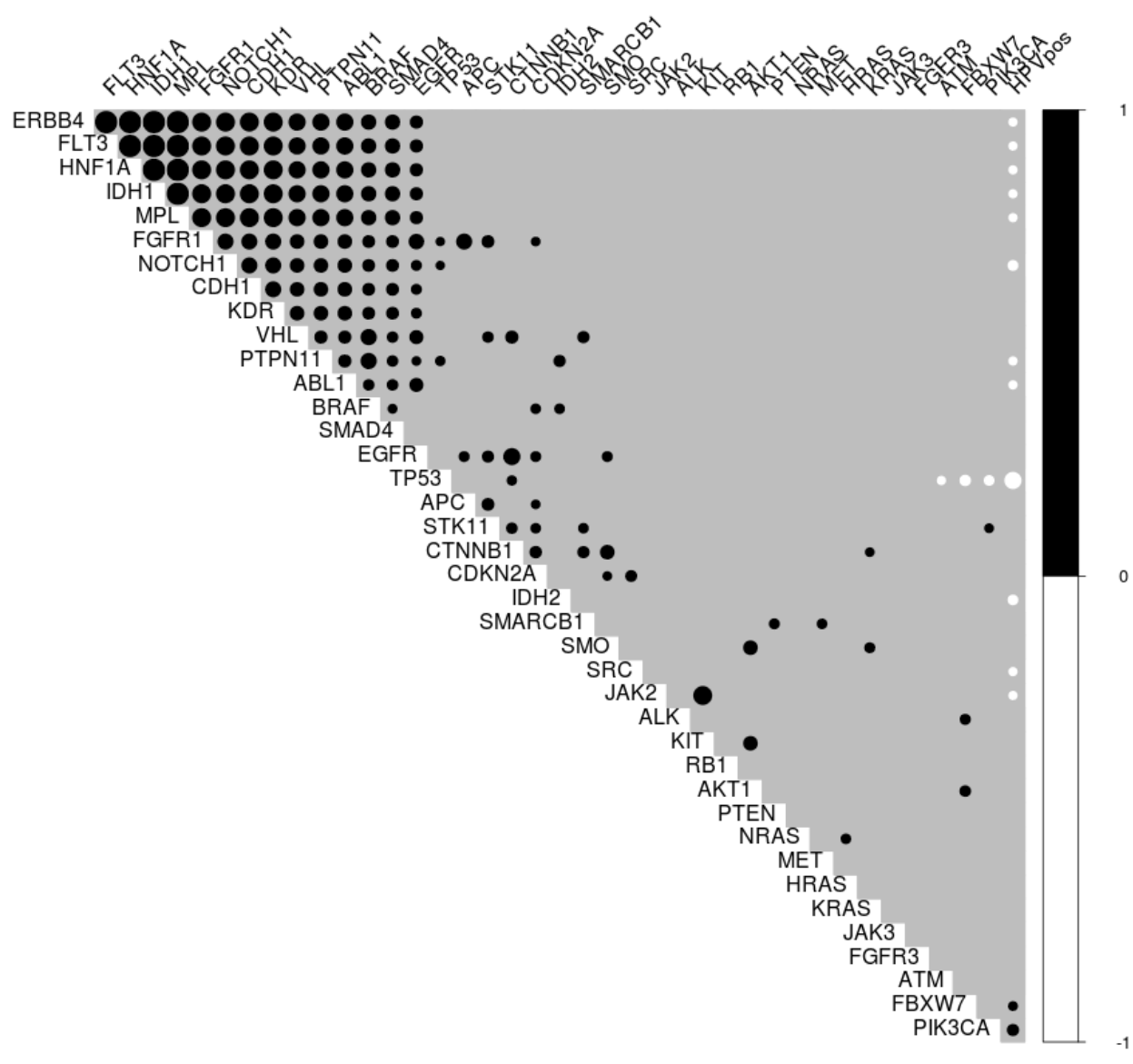

Figure 1: Plot of correlations between gene mutations and HPV status. Only significant correlations $(p<0.05)$ were included. Black circles indicate positive correlations, while white indicate negative correlations. The size of the circle indicates the Spearman correlation coefficient. The black block in the upper left corner shows a number of genes with strong inter-correlations, which mostly have an inverse relationship with HPV status. HPV is negatively associated with many mutations, most strongly TP53, and only positively correlated with PIK3CA and FBXW7 mutations. 
Table 1: Patient and TSCC/BOTSCC characteristics

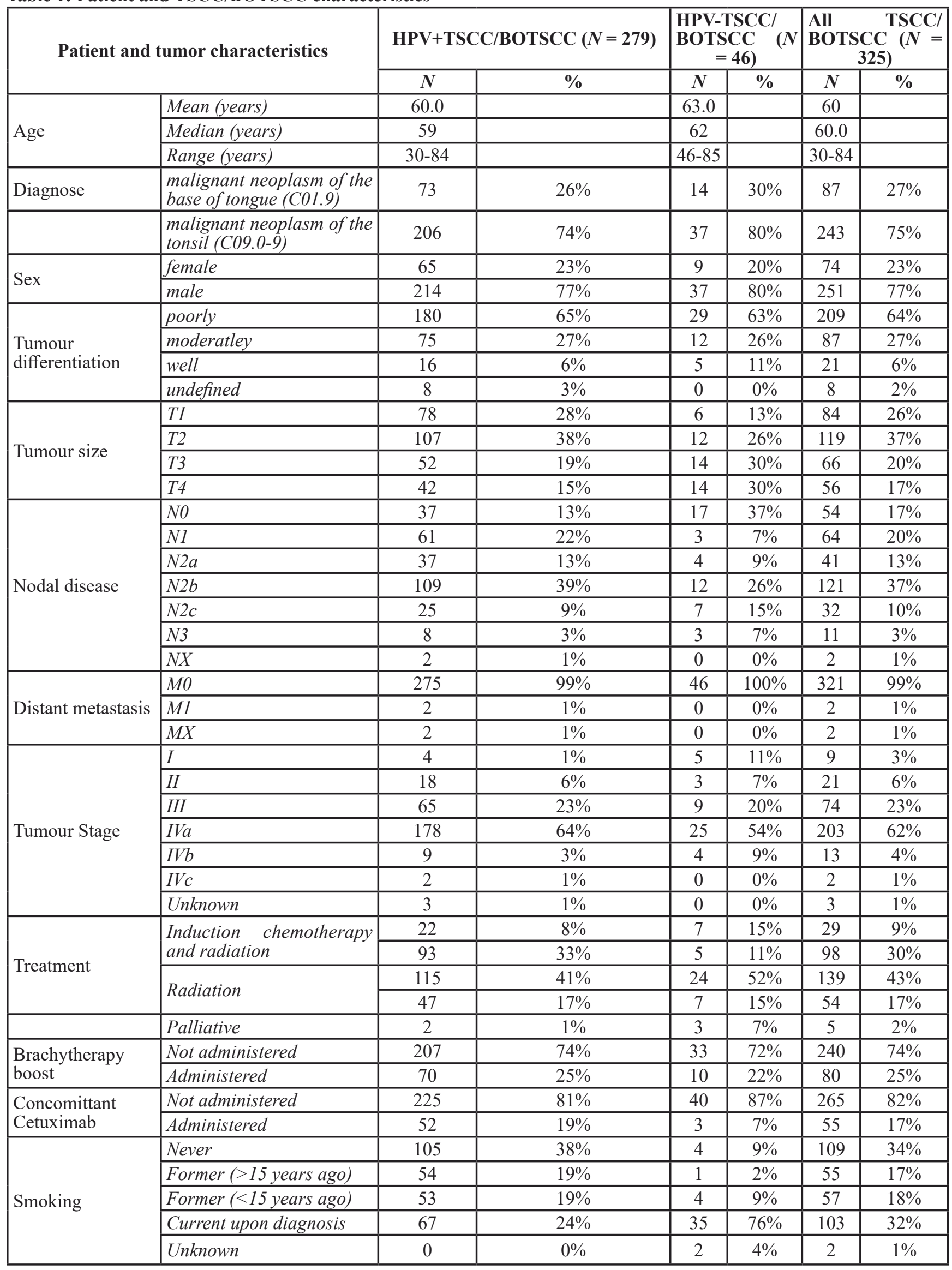


Table 2: Patient and HPV+ HNCUP characteristics

\begin{tabular}{|c|c|c|c|}
\hline \multirow{2}{*}{\multicolumn{2}{|c|}{ Patient and tumor characteristics }} & \multicolumn{2}{|c|}{ HNCUP patients $(N=19)$} \\
\hline & & \multirow{2}{*}{$\frac{N}{63.1}$} & \multirow[t]{2}{*}{$\%$} \\
\hline \multirow{3}{*}{ Age } & Mean (years) & & \\
\hline & Median (years) & 65 & \\
\hline & Range (years) & $36-91$ & \\
\hline \multirow{2}{*}{ Sex } & female & 4 & $21 \%$ \\
\hline & male & 15 & $79 \%$ \\
\hline \multirow{7}{*}{ Nodal disease } & NO & 0 & $0 \%$ \\
\hline & N1 & 7 & $37 \%$ \\
\hline & $N 2 a$ & 2 & $11 \%$ \\
\hline & $N 2 b$ & 6 & $32 \%$ \\
\hline & $N 2 c$ & 2 & $11 \%$ \\
\hline & N3 & 2 & $11 \%$ \\
\hline & $N X$ & 0 & $0 \%$ \\
\hline \multirow{3}{*}{ Distant metastasis } & MO & 19 & $100 \%$ \\
\hline & M1 & 0 & $0 \%$ \\
\hline & $M X$ & 0 & $0 \%$ \\
\hline \multirow{4}{*}{ Smoking } & Never & 4 & $21 \%$ \\
\hline & Former $(>15$ years ago) & & \\
\hline & Former $(<15$ years ago $)$ & & \\
\hline & Current upon diagnosis & & \\
\hline
\end{tabular}

Of note, patients with $\mathrm{HPV}^{+} \mathrm{TSCC} / \mathrm{BOTSCC}$ with mutations in FGFR3 had a worse clinical outcome, depicted as 3-year disease free survival (DFS) $(p=0.002)$ (Figure 2A). Specific data on the FGFR3 mutations are presented in Supplementary Table S1. FGFR3 has previously been reported to be mutated in $\mathrm{HPV}^{+} \mathrm{HNSCC}$ and the common specific variant of FGFR3, S249C, is a putative treatment target in urinary bladder cancer [31, 32]. This was also the most common FGFR 3 variant in our study and was further investigated. Among the $19 \mathrm{HPV}^{+}$ TSCC/BOTSCC patients treated with curative intent and with mutations in the FGFR3 gene, 11 carried the S249C variant. When $\mathrm{HPV}^{+}$TSCC/BOTSCC cases were divided into those carrying the S249C variant, as compared to those with other FGFR3 variants and those with nonmutated FGFR3, patients with tumors carrying S249C had a significantly worse 3-year DFS $(p=0.009)$ (Figure 2B). When $\mathrm{HPV}^{+} \mathrm{TSCC} / \mathrm{BOTSCC}$ was stratified into three strata, those carrying the S249C variant, those with other FGFR3 variants and the rest of the cases, patients with tumors carrying S249C had a significantly shorter 3 -year DFS $(p=0.007)$ (Figure 2C). Presence of FGFR3 mutations were also evaluated in relation to overall survival in $\mathrm{HPV}^{+} \mathrm{TSCC} / \mathrm{BOTSCC}$, but here statistical significance was not obtained (data not shown).
Survival analysis was also performed for the 43 $\mathrm{HPV}^{-} \mathrm{TSCC} / \mathrm{OPSCC}$ cases and for the $19 \mathrm{HPV}^{+} \mathrm{HNCUP}$, where patients were treated with curative intent, for TP53, but not for any other mutations since the other cases were so few. No significant correlations were disclosed between TP53 and clinical outcome for either HPV- TSCC/ BOTSCC or $\mathrm{HPV}^{+} \mathrm{HNCUP}$.

\section{DISCUSSION}

In this report, hotspot mutation regions of 50 cancer related genes were analyzed by NGS in $279 \mathrm{HPV}^{+}$and 46 $\mathrm{HPV}^{-} \mathrm{TSCC} / \mathrm{BOTSCC}$ and $19 \mathrm{HPV}^{+} \mathrm{HNCUP}$. Commonly mutated variants were found in PIK3CA, TP53, FGFR3, FBXW7, PTEN and CDKN2A in $\mathrm{HPV}^{+}$TSCC/BOTSCC, while in $\mathrm{HPV}^{-} \mathrm{TSCC} / \mathrm{BOTSCC}$, mutations were most frequently found in TP53, PIK3CA and IDH2. $\mathrm{HPV}^{+}$ HNCUP showed mutations most often in TP53, PIK3CA and $\mathrm{CDKN} 2 \mathrm{~A}$. The numbers of mutations per tumor were fewer in $\mathrm{HPV}^{+}$TSCC/BOTSCC and HNCUP as compared to $\mathrm{HPV}^{-}$tumors. PIK3CA was most frequently mutated in $\mathrm{HPV}^{+} \mathrm{TSCC} / \mathrm{BOTSCC}$, while TP53 was the most commonly mutated gene in HPV TSCC/BOTSCC. The mutation pattern in $\mathrm{HPV}^{+} \mathrm{HNCUP}$, e.g. with regard to frequency of PIK3CA mutations, was similar to that 

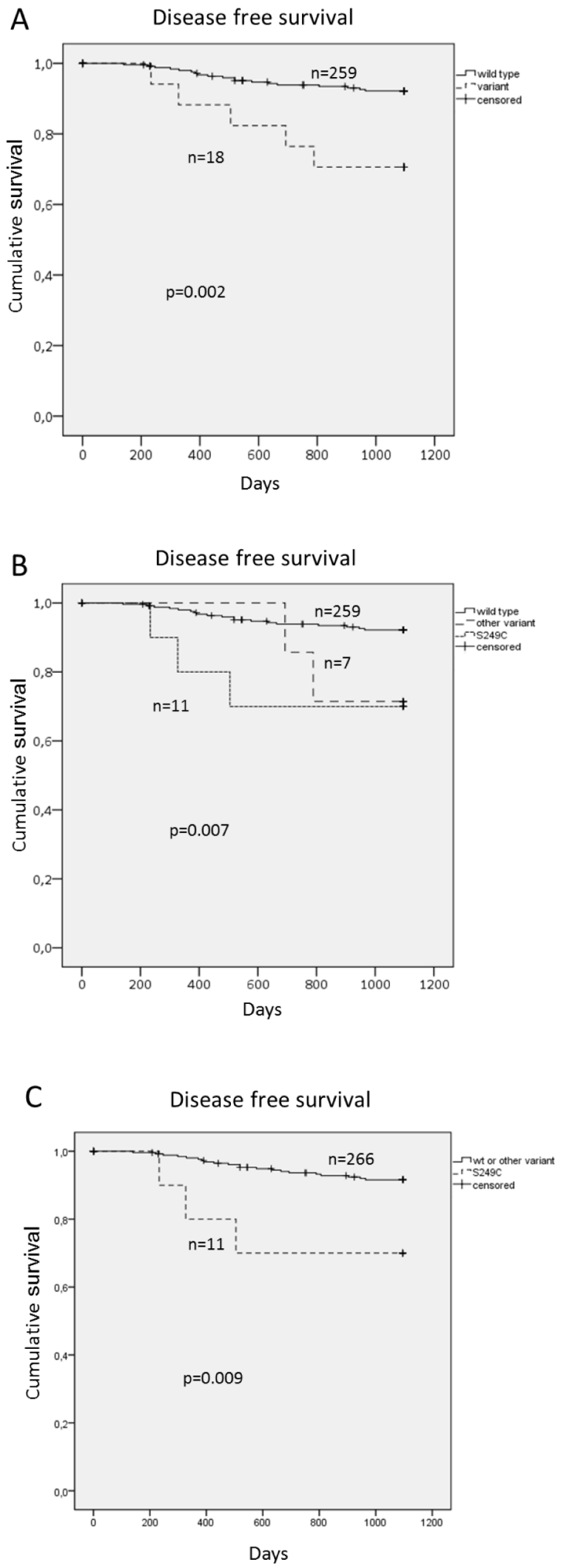

Figure 2: Disease free survival (DFS) for patients with $\mathrm{HPV}^{+}$TSCC/BOTSCC stratified for presence of FGFR3 variants. Cumulative DFS for $\mathrm{HPV}^{+}$TSCC/BOTSCC: A. Stratified for any FGFR3 variant in relation to those with wild type FGFR3. B. Stratified in three categories, those with wild type FGFR3, those with the S249C variant and those with any other variant. C. Stratified between those with the S249C variant and those with wild type or other variants. 
Table 3: Frequency of variants in TSCC/BOTSCC and HNCUP

\begin{tabular}{|c|c|c|c|c|c|c|c|c|c|c|c|c|c|}
\hline \multirow{2}{*}{$\begin{array}{l}\text { Tumor } \\
\text { Gene }\end{array}$} & \multicolumn{4}{|c|}{ HPV+ TSCC/BOTSCC $(n=279)$} & \multicolumn{4}{|c|}{ HPV- TSCC/BOTSCC (N=46) } & \multirow[b]{2}{*}{${ }^{1} p$-values } & \multicolumn{4}{|c|}{ HPV+ HNCUP (n=19) } \\
\hline & $\begin{array}{l}\text { Total } \\
\text { no of } \\
\text { variants }\end{array}$ & $\begin{array}{l}\text { Variants/ } \\
\text { tumor }\end{array}$ & $\begin{array}{l}\text { Tumors } \\
\text { with } \\
\text { variant } \\
\text { gene }\end{array}$ & $\begin{array}{l}\% \text { tumors } \\
\text { with } \\
\text { variant } \\
\text { gene }\end{array}$ & $\begin{array}{l}\text { Total } \\
\text { no of } \\
\text { variants }\end{array}$ & $\begin{array}{l}\text { Variants/ } \\
\text { tumor }\end{array}$ & $\begin{array}{l}\text { Tumors } \\
\text { with } \\
\text { variant } \\
\text { gene }\end{array}$ & $\begin{array}{l}\% \\
\text { tumors } \\
\text { with } \\
\text { variant } \\
\text { gene }\end{array}$ & & $\begin{array}{l}\text { Total } \\
\text { no of } \\
\text { variants }\end{array}$ & $\begin{array}{l}\text { Variants/ } \\
\text { tumor }\end{array}$ & $\begin{array}{l}\text { Tumors } \\
\text { with } \\
\text { variant } \\
\text { gene }\end{array}$ & $\begin{array}{l}\% \\
\text { tumors } \\
\text { with } \\
\text { variant } \\
\text { gene }\end{array}$ \\
\hline ABL1 & 1 & 0.004 & 1 & $0.4 \%$ & 2 & 0.04 & 2 & $4.3 \%$ & & 0 & 0.000 & 0 & $0.0 \%$ \\
\hline AKT1 & 3 & 0.011 & 3 & $1.1 \%$ & 0 & 0.00 & 0 & $0.0 \%$ & & 0 & 0.000 & 0 & $0.0 \%$ \\
\hline ALK & 1 & 0.004 & 1 & $0.4 \%$ & 0 & 0.00 & 0 & $0.0 \%$ & & 0 & 0.000 & 0 & $0.0 \%$ \\
\hline APC & 2 & 0.007 & 2 & $0.7 \%$ & 0 & 0.00 & 0 & $0.0 \%$ & & 1 & 0.053 & 1 & $5.3 \%$ \\
\hline ATM & 7 & 0.025 & 7 & $2.5 \%$ & 1 & 0.02 & 1 & $2.1 \%$ & & 0 & 0.000 & 0 & $0.0 \%$ \\
\hline BRAF & 3 & 0.011 & 3 & $1.1 \%$ & 2 & 0.04 & 2 & $4.3 \%$ & & 0 & 0.000 & 0 & $0.0 \%$ \\
\hline CDH1 & 1 & 0.004 & 1 & $0.4 \%$ & 1 & 0.02 & 1 & $2.1 \%$ & & 0 & 0.000 & 0 & $0.0 \%$ \\
\hline CDKN2A & 13 & 0.047 & 12 & $4.3 \%$ & 3 & 0.06 & 2 & $4.3 \%$ & & 4 & 0.211 & 3 & $15.8 \%$ \\
\hline CSF1R & 0 & 0.000 & 0 & $0.0 \%$ & 0 & 0.00 & 0 & $0.0 \%$ & & 0 & 0.000 & 0 & $0.0 \%$ \\
\hline CTNNB1 & 4 & 0.014 & 3 & $1.1 \%$ & 0 & 0.00 & 0 & $0.0 \%$ & & 0 & 0.000 & 0 & $0.0 \%$ \\
\hline EGFR & 11 & 0.039 & 7 & $2.5 \%$ & 3 & 0.06 & 2 & $4.3 \%$ & & 2 & 0.105 & 2 & $10.5 \%$ \\
\hline ERBB2 & 0 & 0.000 & 0 & $0.0 \%$ & 0 & 0.00 & 0 & $0.0 \%$ & & 0 & 0.000 & 0 & $0.0 \%$ \\
\hline ERBB4 & 0 & 0.000 & 0 & $0.0 \%$ & 1 & 0.02 & 1 & $2.1 \%$ & & 0 & 0.000 & 0 & $0.0 \%$ \\
\hline EZH2 & 0 & 0.000 & 0 & $0.0 \%$ & 0 & 0.00 & 0 & $0.0 \%$ & & 0 & 0.000 & 0 & $0.0 \%$ \\
\hline FBXW7 & 18 & 0.065 & 18 & $6.5 \%$ & 0 & 0.00 & 0 & $0.0 \%$ & & 1 & 0.053 & 1 & $5.3 \%$ \\
\hline FGFR1 & 1 & 0.004 & 1 & $0.4 \%$ & 1 & 0.02 & 1 & $2.1 \%$ & & 0 & 0.000 & 0 & $0.0 \%$ \\
\hline FGFR2 & 0 & 0.000 & 0 & $0.0 \%$ & 0 & 0.00 & 0 & $0.0 \%$ & & 0 & 0.000 & 0 & $0.0 \%$ \\
\hline FGFR3 & 22 & 0.079 & 20 & $7.2 \%$ & 1 & 0.02 & 1 & $2.1 \%$ & & 0 & 0.000 & 0 & $0.0 \%$ \\
\hline FLT3 & 0 & 0.000 & 0 & $0.0 \%$ & 1 & 0.02 & 1 & $2.1 \%$ & & 0 & 0.000 & 0 & $0.0 \%$ \\
\hline GNA11 & 0 & 0.000 & 0 & $0.0 \%$ & 0 & 0.00 & 0 & $0.0 \%$ & & 0 & 0.000 & 0 & $0.0 \%$ \\
\hline GNAQ & 0 & 0.000 & 0 & $0.0 \%$ & 0 & 0.00 & 0 & $0.0 \%$ & & 0 & 0.000 & 0 & $0.0 \%$ \\
\hline GNAS & 0 & 0.000 & 0 & $0.0 \%$ & 0 & 0.00 & 0 & $0.0 \%$ & & 0 & 0.000 & 0 & $0.0 \%$ \\
\hline HNF1A & 0 & 0.000 & 0 & $0.0 \%$ & 1 & 0.02 & 1 & $2.1 \%$ & & 0 & 0.000 & 0 & $0.0 \%$ \\
\hline HRAS & 6 & 0.022 & 5 & $1.8 \%$ & 0 & 0.00 & 0 & $0.0 \%$ & & 0 & 0.000 & 0 & $0.0 \%$ \\
\hline IDH1 & 0 & 0.000 & 0 & $0.0 \%$ & 1 & 0.02 & 1 & $2.1 \%$ & & 0 & 0.000 & 0 & $0.0 \%$ \\
\hline IDH2 & 1 & 0.004 & 1 & $0.4 \%$ & 3 & 0.06 & 3 & $6.4 \%$ & 0.0098 & 2 & 0.105 & 2 & $10.5 \%$ \\
\hline JAK2 & 0 & 0.000 & 0 & $0.0 \%$ & 1 & 0.02 & 1 & $2.1 \%$ & & 0 & 0.000 & 0 & $0.0 \%$ \\
\hline JAK3 & 6 & 0.022 & 6 & $2.2 \%$ & 0 & 0.00 & 0 & $0.0 \%$ & & 0 & 0.000 & 0 & $0.0 \%$ \\
\hline KDR & 1 & 0.004 & 1 & $0.4 \%$ & 1 & 0.02 & 1 & $2.1 \%$ & & 0 & 0.000 & 0 & $0.0 \%$ \\
\hline KIT & 1 & 0.004 & 1 & $0.4 \%$ & 1 & 0.02 & 1 & $2.1 \%$ & & 0 & 0.000 & 0 & $0.0 \%$ \\
\hline KRAS & 9 & 0.032 & 9 & $3.2 \%$ & 0 & 0.00 & 0 & $0.0 \%$ & & 0 & 0.000 & 0 & $0.0 \%$ \\
\hline MET & 4 & 0.014 & 4 & $1.4 \%$ & 1 & 0.02 & 1 & $2.1 \%$ & & 0 & 0.000 & 0 & $0.0 \%$ \\
\hline MLH1 & 0 & 0.000 & 0 & $0.0 \%$ & 0 & 0.00 & 0 & $0.0 \%$ & & 0 & 0.000 & 0 & $0.0 \%$ \\
\hline MPL & 0 & 0.000 & 0 & $0.0 \%$ & 1 & 0.02 & 1 & $2.1 \%$ & & 0 & 0.000 & 0 & $0.0 \%$ \\
\hline NOTCH1 & 0 & 0.000 & 0 & $0.0 \%$ & 2 & 0.04 & 2 & $4.3 \%$ & 0.0197 & 0 & 0.000 & 0 & $0.0 \%$ \\
\hline NPM1 & 0 & 0.000 & 0 & $0.0 \%$ & 0 & 0.00 & 0 & $0.0 \%$ & & 0 & 0.000 & 0 & $0.0 \%$ \\
\hline NRAS & 4 & 0.014 & 4 & $1.4 \%$ & 0 & 0.00 & 0 & $0.0 \%$ & & 0 & 0.000 & 0 & $0.0 \%$ \\
\hline PDGFRA & 0 & 0.000 & 0 & $0.0 \%$ & 0 & 0.00 & 0 & $0.0 \%$ & & 0 & 0.000 & 0 & $0.0 \%$ \\
\hline PIK3CA & 58 & 0.208 & 56 & $20.1 \%$ & 3 & 0.06 & 3 & $6.4 \%$ & 0.0240 & 3 & 0.158 & 3 & $15.8 \%$ \\
\hline PTEN & 16 & 0.057 & 15 & $5.4 \%$ & 1 & 0.02 & 1 & $2.1 \%$ & & 0 & 0.000 & 0 & $0.0 \%$ \\
\hline PTPN11 & 1 & 0.004 & 1 & $0.4 \%$ & 3 & 0.06 & 2 & $4.3 \%$ & & 0 & 0.000 & 0 & $0.0 \%$ \\
\hline RB1 & 3 & 0.011 & 3 & $1.1 \%$ & 0 & 0.00 & 0 & $0.0 \%$ & & 0 & 0.000 & 0 & $0.0 \%$ \\
\hline RET & 0 & 0.000 & 0 & $0.0 \%$ & 0 & 0.00 & 0 & $0.0 \%$ & & 0 & 0.000 & 0 & $0.0 \%$ \\
\hline SMAD4 & 4 & 0.014 & 5 & $1.8 \%$ & 2 & 0.04 & 1 & $2.1 \%$ & & 0 & 0.000 & 0 & $0.0 \%$ \\
\hline SMARCB1 & 4 & 0.014 & 7 & $2.5 \%$ & 0 & 0.00 & 0 & $0.0 \%$ & & 0 & 0.000 & 0 & $0.0 \%$ \\
\hline SMO & 2 & 0.007 & 2 & $0.7 \%$ & 0 & 0.00 & 0 & $0.0 \%$ & & 0 & 0.000 & 0 & $0.0 \%$ \\
\hline SRC & 0 & 0.000 & 0 & $0.0 \%$ & 1 & 0.02 & 1 & $2.1 \%$ & & 0 & 0.000 & 0 & $0.0 \%$ \\
\hline STK11 & 5 & 0.018 & 5 & $1.8 \%$ & 0 & 0.00 & 0 & $0.0 \%$ & & 0 & 0.000 & 0 & $0.0 \%$ \\
\hline TP53 & 44 & 0.158 & 26 & $9.3 \%$ & 40 & 0.85 & 30 & $63.8 \%$ & $<0.0001$ & 11 & 0.579 & 5 & $26.3 \%$ \\
\hline VHL & 2 & 0.007 & 2 & $0.7 \%$ & 1 & 0.02 & 1 & $2.1 \%$ & & 1 & 0.053 & 1 & $5.3 \%$ \\
\hline All genes & 258 & 0.925 & 136 & $48.7 \%$ & 79 & 1.68 & 35 & $74.5 \%$ & 0.0007 & 25 & 1.316 & 9 & $47.4 \%$ \\
\hline
\end{tabular}

${ }^{1} p$-values for number of tumors with variants in HPV positive $v s$. negative TSCC/BOTSCC as evaluated by $\mathrm{chi}^{2}$ or Fisher's exact test.

Only $p$-values $<0.05$ are shown 
of $\mathrm{HPV}^{+}$TSCC/BOTSCC, although the frequency of TP53 mutations was a bit higher than that of $\mathrm{HPV}^{+} \mathrm{TSCC} /$ BOTSCC. Of the variants tested, only FGFR3 variants correlated to clinical outcome in $\mathrm{HPV}^{+}$TSCC/BOTSCC, specified as 3-year DFS, and especially those with the FGFR3 S249C variant had significantly worse prognosis.

The distribution of the various variants, and especially that PIK3CA mutations were more common in $\mathrm{HPV}^{+} \mathrm{TSCC}^{\mathrm{BOTSCC}}$ than in HPV $\mathrm{TSCC}^{-} \mathrm{BOTSCC}$ and vice versa for TP53 was in line with several earlier reports. [30, 31, 33]. However, in the present study the frequency of CDKN2A variants was clearly lower in $\mathrm{HPV}^{-}$ TSCC/BOTSCC as compared to some reports [30, 33-35]. Differences between studies might be due to dissimilarities in the targeted gene region, in the parameters for variant calling and filtering of data.

The finding that the total number of mutations in $\mathrm{HPV}^{+} \mathrm{TSCC}^{-\mathrm{BOTSCC}}$ is lower than in HPV $\mathrm{HSCC}^{-}$ BOTSCC is in concordance with e.g. Tinhofer et al., and could be due to the fact that high risk HPV provides active oncogenes E6 and E7 [30, 36]. Nevertheless, the total number of mutations found in $\mathrm{HPV}^{+}$and $\mathrm{HPV}^{-} \mathrm{TSCC} /$ BOTSCC in other regions needs to be analyzed further, since in this study targeted sequencing was performed using a pre-made cancer panel that covered certain areas of the selected genes. This can also explain some other differences between our study and other studies using larger panels and other experimental approaches, where they indicated larger numbers of mutations and fewer differences between $\mathrm{HPV}^{+}$and HPV $\mathrm{HNSCC}^{-}$[30, 31]. Still, when comparative genomic hybridization was performed, $\mathrm{HPV}^{+}$TSCC and HNSCC respectively, were reported to have fewer gains and losses than $\mathrm{HPV}^{-}$TSCC and HNSCC $[37,38]$.

To our knowledge, the mutational profile of $\mathrm{HPV}^{+}$HNCUP has not been studied before and here we demonstrated that TP53, PIK3CA and CDKN2A were the most frequently altered genes in this subset of HNSCC. That $\mathrm{HPV}^{+} \mathrm{HNCUP}$ had fewer mutations than $\mathrm{HPV}^{-}$TSCC/BOTSCC, and a similar mutation frequency of PIK3CA to HPV+ TSCC/BOTSCC strengthens the hypothesis by others and us that $\mathrm{HPV}^{+} \mathrm{HNCUP}$ originates from $\mathrm{HPV}^{+}$OPSCC [4, 26-28]. Nonetheless, TP53 mutations in $\mathrm{HPV}^{+} \mathrm{HNCUP}$ were more common than in $\mathrm{HPV}^{+}$TSCC/BOTSCC, but less frequent than in $\mathrm{HPV}^{-}$ TSCC/BOTSCC. Thus, there were both similarities and differences between $\mathrm{HPV}^{+} \mathrm{HNCUP}$ and $\mathrm{HPV}^{+} \mathrm{TSCC} /$ BOTSCC. Whether, this is due to that $\mathrm{HPV}^{+} \mathrm{HNCUP}$ should be regarded as $\mathrm{HPV}^{+}$TSCC/BOTSCC metastasis, with additional genomic alterations, needs to be explored further. Notably, the $\mathrm{HPV}^{+} \mathrm{HNCUP}$ group contained fewer never smokers than the $\mathrm{HPV}^{+}$TSCC/BOTSCC group, which to some extent could explain the higher rate of TP53 mutations in the former. Attempts were made to find correlations between commonly occurring variants within each group and clinical outcome. For $\mathrm{HPV}^{+}$
TSCC/BOTSCC, mutations in PIK3CA and TP53 did not correlate to clinical outcome, while notably mutations in FGFR3 and especially the S249C variant correlated to worse prognosis. Variants of FGFR3, including S249C have been reported previously in $\mathrm{HPV}^{+} \mathrm{HNSCC}$, but have to our knowledge not previously been correlated to clinical outcome in $\mathrm{HPV}^{+}$TSCC/BOTSCC [30, 31, 33, 35]. The reported frequency of FGFR3 variants in $\mathrm{HPV}^{+} \mathrm{HNSCC}$ varies between 0 and $24 \%$ [30, 31, 33, 35]. Notably, in bladder cancer the frequency of FGFR3 overexpression is much higher than the frequency of FGFR3 mutations, indicating that in $\mathrm{HPV}^{+} \mathrm{HNSCC}$ more tumors may be affected than can be found in a mutational analysis [39]. There are reports describing that it is possible to target FGFR3, and specifically the S249C variant, e.g. in bladder cancer cell lines, opening an option for more personalized treatment in the future $[32,40]$. Furthermore, although PIK3C and TP53 variants could not be observed to relate to clinical outcome in $\mathrm{HPV}^{+} \mathrm{TSCC} / \mathrm{BOTSCC}$, the possibility still remains that they too could be targeted in the future and present a possibility for more personalized treatment.

In this investigation, mutation in TP53 did not correlate to clinical outcome in the HPV cancer group, which differs from a previous report, where mutated TP53 conferred worse outcome in HPV- HNSCC [30]. There is no evident explanation for this discrepancy however there are differences in the choice of sequencing methods and sequencing gene panels as well as number and type of patients included for the analysis [30]. Furthermore, in this study TP53 mutations were defined as of moderate and of high impact and correlated to 3-year DFS, while in the other report the distinction was related to degree of hotspot missense TP53 mutations and correlated to locoregional recurrence [30]. Other mutations in $\mathrm{HPV}^{-}$ TSCC/BOTSCC, such as PIK3CA, were not analyzed in relation to clinical outcome due to the limited numbers of cases making it a target for further analysis. However, no such correlation was previously identified despite the larger number of $\mathrm{HPV}^{-} \mathrm{HNSCC}$ cases in the work of Tinhofer et al [30].

There are limitations in this study in that only hotspot mutations of 50 oncogenes and tumor suppressor genes were analyzed, and that our inquiry was retrospective. Furthermore, only $19 \mathrm{HPV}^{+} \mathrm{HNCUP}$ cases were included. Nevertheless, some interesting findings were still observed.

To conclude, when studying hotspot mutations in 50 oncogenes and tumor suppressor genes, the frequency of mutations per tumor were similar and fewer in $\mathrm{HPV}^{+}$ TSCC/BOTSCC and $\mathrm{HPV}^{+} \mathrm{HNCUP}$, compared to, and differing from HPV ${ }^{-}$TSCC/BOTSCC. Furthermore, for the first time specific FGFR3 mutations (S249C) in $\mathrm{HPV}^{+} \mathrm{TSCC}^{\mathrm{BOTSCC}}$ were disclosed as a significant risk for worse clinical outcome, also opening up for novel therapeutic options for these patients. 


\section{MATERIALS AND METHODS}

\section{Patients and tumor characteristics}

Patients diagnosed with TSCC (ICD-10 code C09.0-9) or BOTSCC (ICD-10 code C01.9) or HNCUP/ secondary and unspecified malignant neoplasm of lymph nodes of head, face and neck (ICD-10 C77.0) between 2000-2011 at Karolinska University Hospital were included in the study. Having an $\mathrm{HPV}^{+}$TSCC/BOTSCC in this study was defined as having an HPV DNA positive tumor combined with overexpressing $\mathrm{p} 16^{\mathrm{INK} 4 \mathrm{~A}}(\mathrm{p} 16)$, and if not p16 positive, as in one case, instead expressing HPV16 E7, while HPV TSCC/BOTSCC was defined as having no HPV DNA. TSCC/BOTSCC not fulfilling these criteria, i.e. with dubious HPV status, were excluded from the analysis. By this definition this investigation initially included FFPE biopsy material from $297 \mathrm{HPV}^{+} \mathrm{TSCC} /$ BOTSCC and $51 \mathrm{HPV}^{-}$TSCC/BOTSCC. Data on presence or absence of HPV DNA and p16 expression and HPV16 mRNA expression in the biopsies were derived from previous studies [16, 22, 23]. HPV DNA and p16 data on the $20 \mathrm{HPV}^{+} \mathrm{HNCUP}$ were obtained from a previous report where all cases but two overexpressed p16 [4]. The study was performed according to permission 2009/127831/4 from the Ethical Committee at Karolinska Institutet.

\section{DNA extraction and analysis of HPV DNA and p16 overexpression}

DNA was extracted and HPV DNA status was assayed by a PCR-based bead based multiplex assay on a MagPix instrument (Luminex Inc.) as described previously [41]. p16 expression was examined using the monoclonal antibody (mAb) clone JC8 (Santa Cruz Biotech, Santa Cruz, CA, USA) [5, 22, 24].

\section{Library preparation}

Hotspot regions in cancer related genes were analyzed by targeted amplification by PCR using the Ion AMpliSeq Cancer Hotspot Panel v2 (CHPv2 - Thermo Fisher Scientific), which covers 2800 hotspots in the following 50 genes; ABL1, AKT1, ALK, APC, ATM, BRAF, CDH1, CDKN2A, CSF1R, CTNNB1, EGFR, ERBB2, ERBB4, EZH2, FBXW7, FGFR1, FGFR2, FGFR3, FLT3, GNA11, GNAQ, GNAS, HNF1A, HRAS, IDH1, IDH2, JAK2, JAK3, KDR, KIT, KRAS, MET, MLH1, MPL, NOTCH1, NPM1, NRAS, PDGFRA, PIK3CA, PTEN, PTPN11, RB1, RET, SMAD4, SMARCB1, SMO, SRC, STK11, TP53 and VHL.

Amplicon libraries were prepared according to the manufacturer's protocol. In brief, $10 \mathrm{ng}$ of genomic
DNA from tumor samples was measured by Qubit 2.0 Fluorometer (Thermo Fisher Scientific) and amplified in a single multiplex PCR reaction obtaining 207 amplicons with sizes ranging from 49 to $140 \mathrm{bp}$. Next, amplicons were treated with FuPa Reagent (Thermo Fisher Scientific) to partially digest the primers and phosphorylate the amplicon ends, and the products were ligated to the sequencing adapters with 96 unique Ion Xpress Barcodes (Thermo Fisher Scientific) according to the manufacturer's instructions. After AMPure beads purification (Beckman Coulter), all barcoded libraries were quantified by the Agilent 2100 Bioanalyser and Agilent High Sensitivity DNA Kit (Agilent Technologies). The final library concentrations were standardized to $100 \mathrm{pM}$ in low TrisEDTA (TE) buffer.

Emulsion PCR and enrichment were performed on an Ion One Touch System by using the Ion PI Hi-Q OT2 200 Kit (Thermo Fisher Scientific) according to the manufacturer's instructions. Lastly, 96 pooled samples were loaded on a Ion P1 chip and sequenced on the Ion Proton benchtop sequencing platform using the Ion PI Hi-Q Sequencing 200 Kit (Thermo Fisher Scientific).

The Ion Torrent Variant Caller Plugin v5.0 was used to align reads to the reference genome hg19.

\section{Variant calling}

The Ion Torrent platform-specific pipeline software Torrent Suite used data from the initial Ion Proton runs to generate sequence reads, trim adapter sequences and filter and remove poor signal profile reads. Then, Torrent Suite Software v5.0, with a plug-in "variant caller v5.0" program (TVC), was used to call variants from the initial sequencing data. In order to eliminate base calling errors, several filtering steps were employed to generate final variant calling. First, variants samples with poor DNA quality were excluded, defined as $<80 \%$ on-target reads and/or mean coverage $<400$ reads. Additional filters for variant calling were fixed at an average total coverage depth $>100$, single variant coverage $>20$, a variant allele frequency (VAF) between 5\% and 90\%. Furthermore, low impact variants were not retained, as well as germline variants, defined as variants with VAF $>1 \%$ in any of the population genome databases; 1000 genomes [42] (All1000genomes and Eur1000genomes) and ExAC [43] databases. Also, two additional common SNP/MNPs, present in the NCBI dbSNP [44] database but not present in the COSMIC database [45], were filtered out. Lastly, dubious variants were visually inspected using Integrative Genomics Viewer (IGV) software.

\section{Statistical analysis}

Clinical outcome was measured as 3-year diseasefree survival (DFS) from the date of diagnosis. An event 
was defined as recurrence in the disease. Patients who were never tumor-free were counted as having relapsed on day 0 , while patients who died without prior recurrence were censored at that time-point. Statistical calculations were performed using IBM SPSS Statistics software (Version 23.0; IBM Corp., Armonk, NY, USA). Survival curves and 3-year DFS were calculated using the KaplanMeier method and differences in survival were tested using the log-rank test. Frequencies of variants in the different genes in Table 3 were compared by the Chi-square or Fisher's exact test. Two-sided p-values were reported for all analyses and p-values below 0.05 were considered as significant. Correlations were calculated between all mutated genes and HPV status, using Spearman's test. Any mutation in a gene was coded as 1 and absence of any mutation as 0 . Significance values of correlations were calculated with the asymptotic t-approximation, using the cor.test function in $\mathrm{R}$.

\section{ACKNOWLEDGMENTS}

This research was supported by the Swedish Cancer Foundation, the Stockholm Cancer Society, the Swedish Cancer and Allergy Foundation, the Sigurd and Elsa Goljes Foundation, the Stockholm City Council and Karolinska Institutet, Sweden. The computations were performed on resources provided by SNIC through Uppsala Multidisciplinary Center for Advanced Computational Science (UPPMAX) under Project b2015372.

\section{CONFLICTS OF INTEREST}

The authors have no relevant conflicts of interest to disclose.

\section{REFERENCES}

1. Mellin H, Friesland S, Lewensohn R, Dalianis T, and Munck-Wikland E. Human papillomavirus (HPV) DNA in tonsillar cancer: clinical correlates, risk of relapse, and survival. Int J Cancer. 2000; 89: 300-4.

2. Dahlgren L, Dahlstrand HM, Lindquist D, Högmo A, Björneståhl L, Lindholm J, Lundberg B, Dalianis T, and Munck-Wikland E. Human papillomavirus is more common in base of tongue than in mobile tongue cancer and is a favorable prognostic factor in base of tongue cancer patients. Int. J Cancer. 2004; 112: 1015-9.

3. Attner P, Du J, Näsman A, Hammarstedt L, Ramqvist T, Lindholm J, Marklund L, Dalianis T, and Munck-Wikland E. Human papillomavirus and survival in patients with base of tongue cancer. Int J Cancer. 2011; 128: 2892-7.

4. Sivars L, Nasman A, Tertipis N, Vlastos A, Ramqvist T, Dalianis T, Munck-Wikland E, and Nordemar S. Human papillomavirus and p53 expression in cancer of unknown primary in the head and neck region in relation to clinical outcome. Cancer Med. 2014; 3: 376-84.

5. Dalianis T. Human papillomavirus and oropharyngeal cancer, the epidemics, and significance of additional clinical biomarkers for prediction of response to therapy. Int $\mathrm{J}$ Oncol. 2014; 244: 1799-1805.

6. Marklund L, Näsman A, Ramqvist T, Dalianis T, MunckWikland E, and Hammarstedt L. Prevalence of human papillomavirus and survival in oropharyngeal cancer other than tonsil or base of tongue cancer. Cancer Med. 2012; 1 : 82-8.

7. Robinson KL and Macfarlane GJ. Oropharyngeal cancer incidence and mortality in Scotland: are rates still increasing? Oral Oncol. 2003; 39: 31-3.

8. Hammarstedt L, Lindquist D, Dahlstrand H, Romanitan M, Dahlgren LO, Joneberg J, Creson N, Lindholm J, Ye W, Dalianis T, and Munck-Wikland E. Human papillomavirus as a risk factor for the increase in incidence of tonsillar cancer. Int J Cancer. 2006; 119: 2620-3.

9. Sturgis EM, and Cinciripini PM. Trends in head and neck cancer incidence in relation to smoking prevalence: an emerging epidemic of human papillomavirus-associated cancers? Cancer. 2007; 110: 1429-35.

10. Nasman A, Attner P, Hammarstedt L, Du J, Eriksson M, Giraud G, Ahrlund-Richter S, Marklund L, Romanitan M, Lindquist D, Ramqvist T, Lindholm J, Sparén P et al. Incidence of human papillomavirus (HPV) positive tonsillar carcinoma in Stockholm, Sweden: An epidemic of viralinduced carcinoma? Int J Cancer. 2009; 125: 362-6.

11. Braakhuis BJ, Visser O, and Leemans CR. Oral and oropharyngeal cancer in The Netherlands between 1989 and 2006: Increasing incidence, but not in young adults. Oral Oncol. 2009; 45: e85-9.

12. Attner $\mathrm{P}, \mathrm{Du} \mathrm{J}$, Nasman A, Ramqvist $\mathrm{T}$, Lindholm J, Marklund L, Dalianis T, and Munck-Wikland E. The role of human papillomavirus in the increased incidence of base of tongue cancer. Int J Cancer. 2010; 126: 2879-84.

13. Chaturvedi AK, Engels EA, Pfeiffer RM, Hernandez BY, Xiao W, Kim E, Jiang B, Goodman MT, Sibug-Saber M, Cozen W, Liu L, Lynch CF, Wentzensen N, et al. Human papillomavirus and rising oropharyngeal cancer incidence in the United States. J Clin Oncol. 2011; 29: 4294-301.

14. Näsman A, Nordfors C, Holzhauser S, Vlastos A, Tertipis N, Hammar U, Hammarstedt-Nordenvall L, Marklund L, Munck-Wikland E, Ramqvist T, Bottai M, and Dalianis T. Incidence of human papillomavirus positive tonsillar and base of tongue carcinoma: a stabilisation of an epidemic of viral induced carcinoma? Eur J Cancer. 2015; 51: 55-61

15. Ang KK, Harris J, Wheeler R, Weber R, Rosenthal DI, Nguyen-Tân PF, Westra WH, Chung CH, Jordan RC, Lu C, Kim H, Axelrod R, Silverman CC, et al. Human papillomavirus and survival of patients with oropharyngeal cancer. N Engl J Med. 2010; 363: 24-35.

16. Näsman A, Andersson E, Marklund L, Tertipis N, Hammarstedt-Nordenwall L, Nyberg T, Masucci GV, 
Munck-Wikland E, Ramqvist T, and Dalianis T. HLA class I and II expression in oropharyngeal squamous cell carcinoma in relation to tumour HPV status and clinical outcome. PloS One. 2013; 8: e77025.

17. Näsman A, Nordfors C, Grün N, Munck-Wikland E, Ramqvist $\mathrm{T}$, Marklund L, Lindquist $\mathrm{D}$, and Dalianis T. Absent/weak CD44 intensity and positive human papillomavirus (HPV) status in oropharyngeal squamous cell carcinoma indicates a very high survival. Cancer Med. 2013; 2: 507-18.

18. Tertipis N, Haeggblom L, Nordfors C, Grün N, Näsman A, Vlastos A, Dalianis T, and Ramqvist T. Correlation of LMP10 expression and clinical outcome in Human Papillomavirus (HPV) positive and HPV-negative tonsillar and base of tongue cancer. PLoS One. 2014; 9: e 95624.

19. Lindquist D, Näsman A, Tarján M, Henriksson R, Tot T, Dalianis T, and Hedman H. Expression of LRIG1 is associated with good prognosis and human papillomavirus status in oropharyngeal cancer. Br J Cancer. 2014; 110: 1793-1800.

20. Tertipis N, Villabona L, Nordfors C, Näsman A, Ramqvist T, Vlastos A, Masucci G, and Dalianis T. HLA-A*02 in relation to outcome in human papillomavirus positive tonsillar and base of tongue cancer. Anticancer Res. 2014; 34: 2369-75.

21. Nordfors C, Grün N, Tertipis N, Ährlund-Richter A, Haeggblom L, Sivars L, Du J, Nyberg T, Marklund L, Munck-Wikland E, Näsman A, Ramqvist T, and Dalianis T. CD8+ and CD4+ tumour infiltrating lymphocytes in relation to human papillomavirus status and clinical outcome in tonsillar and base of tongue squamous cell carcinoma. Eur J Cancer. 2013; 49: 2522-30.

22. Ramqvist T, Mints M, Tertipis T, Näsman A, Romanitan M, and Dalianis T. Studies on human papillomavirus (HPV) 16 E2, E5 and E7 mRNA in HPV-positive tonsillar and base of tongue cancer in relation to clinical outcome and immunological parameters. Oral Oncol. 2015; 51: 1121-31.

23. Rietbergen MM, Martens-de Kemp SR, Bloemena E, Witte BI, Brink A, Baatenburg de Jong RJ, Leemans $\mathrm{CR}$, Braakhuis BJ, and Brakenhoff RH. Cancer stem cell enrichment marker CD98: a prognostic factor for survival in patients with human papillomavirus-positive oropharyngeal cancer. Eur J Cancer. 2014; 50: 765-73.

24. Tertipis N, Hammar U, Näsman A, Vlastos A, Nordfors C, Grün N, Ährlund-Richter A, Sivars L, Haeggblom L, Marklund L, Hammarstedt-Nordenvall L, Chaturvedi AK, Munck-Wikland E, et al. A model for predicting clinical outcome in patients with human papillomavirus-positive tonsillar and base of tongue cancer. Eur. J Cancer. 2015; 51: $1580-7$.

25. Mirghani H, Amen F, Blanchard P, Moreau F, Guigay J, Hartl DM, and Lacau St Guily J. Treatment de-escalation in HPV-positive oropharyngeal carcinoma: ongoing trials, critical issues and perspectives. Int J Cancer. 2015; 136: 1494-1503.
26. Jensen DH, Hedback N, Specht L, Høgdall E, Andersen E, Therkildsen MH, Friis-Hansen L, Norrild B, von Buchwald C. Human papillomavirus in head and neck squamous cell carcinoma of unknown primary is a common event and a strong predictor of survival. PLoS One. 2014: 9: e110456.

27. Park GC, Lee M, Roh JL, Yu MS, Choi SH, Nam SY, Kim SY, and Cho KJ. Human papillomavirus and p16 detection in cervical lymph node metastases from an unknown primary tumor. Oral Oncol 2012; 48: 1250-6.

28. Tribius S, Hoffmann AS, Bastrop S, Görögh T, Haag J, Röcken C, Clauditz T, Grob T, Wilczak W, Tennstedt P, Borcherding A, Petersen C, and Hoffmann M. HPV status in patients with head and neck of carcinoma of unknown primary site: HPV, tobacco smoking, and outcome. Oral Oncol. 2012; 48: 1178-84.

29. Compton AM, Moore-Medlin T, Herman-Ferdinandez L, Clark C, Caldito GC, Wang XI, Thomas J, Abreo FW, and Nathan CO. Human papillomavirus in metastatic lymph nodes from unknown primary head and neck squamous cell carcinoma. Otolaryngol Head Neck Surg. 2011; 145: 51-7.

30. Tinhofer I, Budach V, Saki M, Konschak R, Niehr F, Jöhrens K, Weichert W, Linge A, Lohaus F, Krause M, Neumann K, Endris V, Sak A, et al. Targeted nextgeneration sequencing of locally advanced squamous cell carcinomas of the head and neck reveals druggable targets for improving adjuvant chemoradiation. Eur J Cancer. 2016; 57: 78-86.

31. Seiwert TY, Zuo Z, Keck MK, Khattri A, Pedamallu CS, Stricker T, Brown C, Pugh TJ, Stojanov P, Cho J, Lawrence MS, Getz G, Brägelmann J, et al. Integrative and comparative genomic analysis of HPV-positive and HPVnegative head and neck squamous cell carcinomas. Clin Cancer Res. 2015; 21: 632-41.

32. Miyake M, Ishii M, Koyama N, Kawashima K, Kodama T, Anai S, Fujimoto K, Hirao Y, and Sugano K. 1-tert-butyl-3[6-(3,5-dimethoxy-phenyl)-2-(4-diethylamino-butylamino)pyrido[2,3-d]pyrimidin-7-yl]-urea (PD173074), a selective tyrosine kinase inhibitor of fibroblast growth factor receptor-3 (FGFR3), inhibits cell proliferation of bladder cancer carrying the FGFR3 gene mutation along with upregulation of p27/Kip1 and G1/G0 arrest. J Pharmacol Exp Ther. 2010; 332: 795-802.

33. Chung CH, Guthrie VB, Masica DL, Tokheim C, Kang H, Richmon J, Agrawal N, Fakhry C, Quon H, Subramaniam RM, Zuo Z, Seiwert T, Chalmers ZR, et al. Genomic alterations in head and neck squamous cell carcinoma determined by cancer gene-targeted sequencing. Ann Oncol. 2015; 26:1216-23.

34. Morris LG, Chandramohan R, West L, Zehir A, Chakravarty D, Pfister DG, Wong RJ, Lee NY, Sherman EJ, Baxi SS, Ganly I, Singh B, et al. The Molecular Landscape of Recurrent and Metastatic Head and Neck Cancers: Insights From a Precision Oncology Sequencing Platform. JAMA Oncol. 2016. doi: 10.1001/jamaoncol.2016.1790. [Epub ahead of print]. 
35. Lechner M, Frampton GM, Fenton T, Feber A, Palmer G, Jay A, Pillay N, Forster M, Cronin MT, Lipson D, Miller VA, Brennan TA, Henderson S, et al. Targeted nextgeneration sequencing of head and neck squamous cell carcinoma identifies novel genetic alterations in HPV + and HPV- tumors. Genome Med. 2013; 5: 49.

36. Tommasino M. The human papillomavirus family and its role in carcinogenesis. Semin Cancer Biol. 2014; 26: 13-21.

37. Dahlgren L, Mellin H, Wangsa D, Heselmeyer-Haddad K, Björnestål L, Lindholm J, Munck-Wikland E, Auer G, Ried $\mathrm{T}$, Dalianis T. Comparative genomic hybridization analysis of tonsillar cancer reveals a different pattern of genomic imbalances in human papillomavirus-positive and -negative tumors. Int J Cancer. 2003; 107: 244-9.

38. Smeets SJ, Braakhuis BJ, Abbas S, Snijders PJ, Ylstra B, van de Wiel MA, Meijer GA, Leemans CR, and Brakenhoff RH. Genome-wide DNA copy number alterations in head and neck squamous cell carcinomas with or without oncogene-expressing human papillomavirus Oncogene. 2006; 25: 2558-68.

39. Tomlinson DC, Baldo O, Harnden P, and Knowles MA. FGFR3 protein expression and its relationship to mutation status and prognostic variables in bladder cancer. J Pathol. 2007; 213: 91-8.

40. Gust KM, McConkey DJ, Awrey S, Hegarty PK, Qing J, Bondaruk J, Ashkenazi A, Czerniak B, Dinney CP, and Black PC. Fibroblast growth factor receptor 3 is a rational therapeutic target in bladder cancer. Mol Cancer Ther. 2013; 12: 1245-54.
41. Nordfors C, Vlastos A, Du J, Ährlund-Richter A, Tertipis N, Grün N, Romanitan M, Haeggblom L, Roosaar A, Dahllöf $\mathrm{G}$, Donà $\mathrm{MG}$, Benevolo $\mathrm{M}$, Ramqvist $\mathrm{T}$, et al. Human papillomavirus prevalence is high in oral samples of patients with tonsillar and base of tongue cancer. Oral Oncol. 2015; 50: 491-7.

42. The 1000 Genomes Project Consortium. A Global Reference for Human Genetic Variation. Nature. 2015; 526: 68-74.

43. Lek M, Karczewski KJ, Minikel EV, Samocha KE, Banks E, Fennell T, O'Donnell-Luria AH, Ware JS, Hill AJ, Cummings BB, Tukiainen T, Birnbaum DP, Kosmicki JA, et al. Analysis of Protein-Coding Genetic Variation in 60,706 Humans. Nature. 2016; 536: 285-91.

44. Sherry S T, Ward MH, Kholodov M, Baker J, Phan L, Smigielski EM, and Sirotkin K. dbSNP: The NCBI Database of Genetic Variation. Nucleic Acids Research. 2001; 29: 308-11.

45. Bamford S, Dawson E, Forbes S, Clements J, Pettett R, Dogan A, Flanagan A, Teague J, Futreal PA, Stratton MR, and Wooster R. The COSMIC (Catalogue of Somatic Mutations in Cancer) Database and Website. British Journal of Cancer. 2004; 91: 355-8. 